\section{Acta 3iologica Gibirica}

Journal of Biology

Founded in 2015
Altai State University

www.asu.ru

ISSN 2412-1908

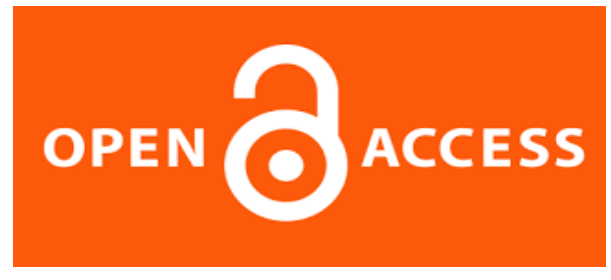

Acta Biologica Sibirica, 2018, 4(3), 102-107

UDC 632.937.03

\title{
Distribution of ground beetles of the genus Poecilus Bonelli, 1810 (Coleoptera, Carabidae) in the agrolandscape in Northwestern Russia
}

\author{
O.G. Guseva \\ All-Russian Institute of Plant Protection, Podbelskogo 3, St.Petersburg, Pushkin, 196608, Russia
}

Three species of the genus Poecilus Bonelli, 1810: P. cupreus (L.), P. versicolor (Sturm) and P. lepidus (Leske) inhabit the agrolandscapes in Northwestern Russia. Two the most numerous species are $P$. cupreus and $P$. versicolor. They differ by the areas they occupy and their abundance on the various parts of a landscape. $P$. cupreus occurred mostly on the fields, more rarely - on their boundaries. $P$. versicolor lives mostly on the field boundaries but can be also seen on the cultivated lands and forest edges. Some $P$. lepidus individuals can be observed only on dry and warmed open areas. The population of the ground beetles of the genus Poecilus varies significantly between the field and its boundaries.

Key words: ground beetles, Poecilus, agrolandscape, Northwestern Russia

\section{Распределение жужелиц рода Роecilus Bonelli, 1810 (Coleoptera, Carabidae) в агроландшафте на Северо- Западе России}

\author{
О.Г. Гусева \\ Всероссийский НИи защиты растений, Санкт-Петербург, Пушкин, шоссе Подбельского, 3, 196608, \\ Россия \\ E-mail: olgaguseva-2011@yandex.ru
}

\begin{abstract}
В агроландшафтах Северо-Запада России обитают три вида рода Poecilus Bonelli, 1810: P. cupreus (L.), P. versicolor (Sturm) и $P$. lepidus (Leske). Два массовых вида - P. cupreus и P. versicolor отличаются по занимаемому пространству и обилию на различных участках ландшафта. Р. сupreus встречается в основном на полях, реже на их обочинах. $P$. versicolor обитает преимущественно на обочинах полей, реже встречается на возделываемых землях и опушках леса. Третий вид, P. lepidus, отмечен единично только на сухих прогреваемых открытых участках, как на полях, так и на обочинах. В целом население жужелиц рода Роecilus на поле и его обочинах существенно отличается. Ключевые слова: жужелицы, Роесіlus, агроландшафт, Северо-Запад России
\end{abstract}




\section{Введение}

Представители рода Poecilus Bonelli, 1810 относятся к числу самых распространенных и многочисленных жужелиц агроландшафтов. На территории Северо-Запада России встречаются три вида этого рода: P. cupreus (L.), P. versicolor (Sturm) и P. lepidus (Leske). Наибольшее значение как энтомофаг вредителей сельского хозяйства имеет Poecilus cupreus - вид с обширным ареалом, являющийся доминантным в различных агроценозах достаточно удаленных друг от друга географических районов Европы и Кавказа (Koval, Belousov, 2001). Ocoби P. cupreus являются многоядными хищниками с очень широкой пищевой специализацией (Guseva, Koval, 2010; Sunderland, 2002). Среди жужелиц P. сupreus на территории европейской части России является важнейшим энтомофагом колорадского жука Leptinotarsa decemlineata Say (Koval, 2009). В агроладшафтах Ленинградской области P. сирrеи занимает первое место по частоте встречаемости среди жужелиц (Guseva et al., 2015); он является массовым видом в различных районах и на почвах различного механического состава (Guseva, Koval, 2008; Koval, Guseva, 2008). P. versicolor по частоте встречаемости в агроландшафтах Ленинградской области занимает среди жужелиц лишь девятое место (Guseva et al., 2015). Представители данного вида предпочитают более легкие по механическому составу почвы. По мнению известного шведского карабидолога Карла Линдрота (Lindroth, 1985), P. versicolor является более ксерофильным по сравнению с Р. сupreus. Третий вид, Р. lepidus, на Северо-Западе России встречается относительно редко. Территории, на которых обитают все три вида рода Роесіlus, представляют интерес с точки зрения изучения экологических предпочтений каждого из них. Такая возможность представилась при проведении комплексных учетов наземных беспозвоночных на выровненной территории опытного полигона Меньковского филиала Агрофизического НИИ (МФ АФИ) в Гатчинском районе Ленинградской области. Выявление особенностей экологической приуроченности отдельных видов рода Роесіlus и оценка обилия этих жужелиц на отдельных участках агроландшафта важны для поиска путей увеличения численности этих энтомофагов.

\section{Материалы и методы}

Основные исследования проводились в 2008 году в Гатчинском р-не Ленинградской области, на территории МФ АФИ, на поле яровой пшеницы и примыкающей к нему обочине, заросшей разнотравьем и кустарником и переходящей в опушку смешанного леса. Почва на опытном полигоне МФ АФИ - дерново-подзолистая супесчаная.

Для изучения напочвенных хищных жуков на экспериментальном участке были установлены почвенные ловушки - 0.5 литровые стеклянные банки (рис. 1), на 1/3-1/2 объема наполненные 4 \% раствором формалина.

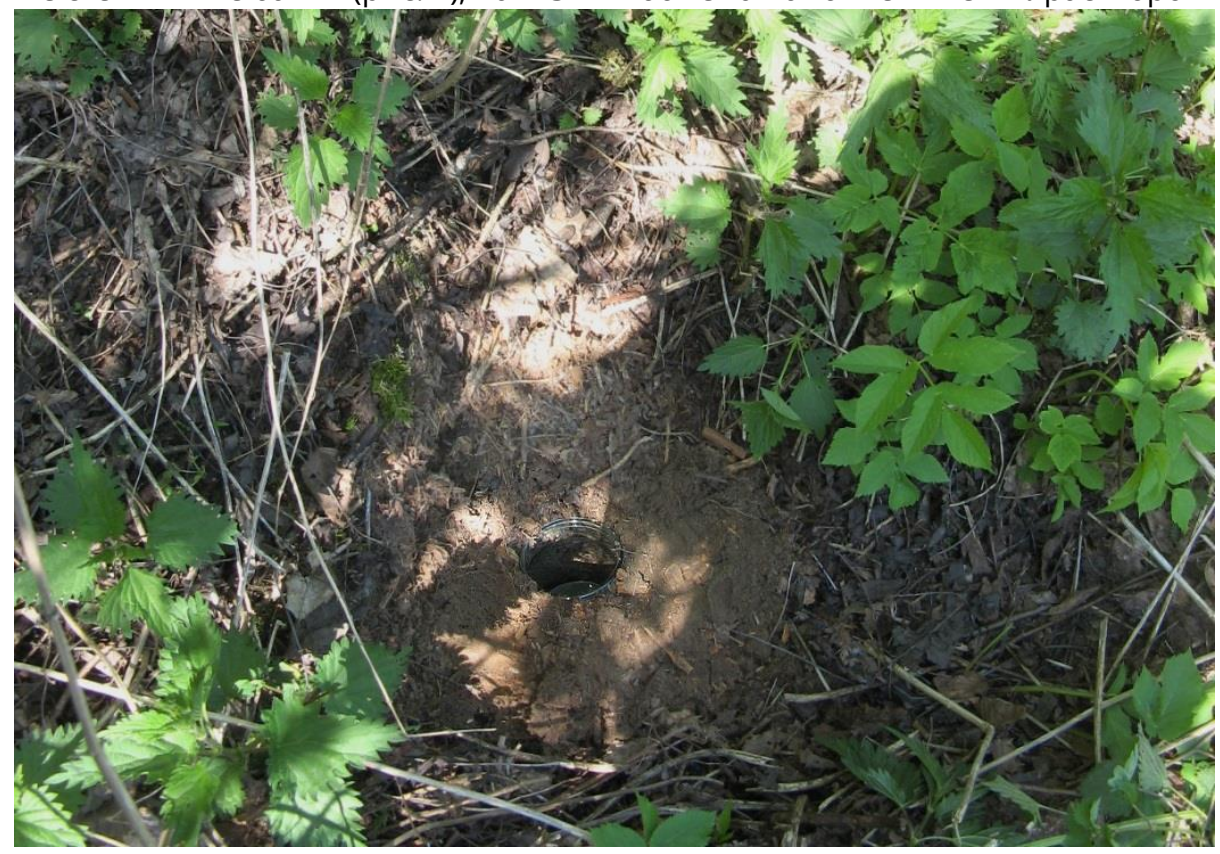

Рис. 1. Почвенная ловушка на опушке леса.

Всего было установлено 12 ловушек на одной линии на расстоянии 10 м одна от другой (рис. 2). На рисунке 5 цифрами на цветной шкале обозначены места расположения ловушек на аэрофотоснимке места проведения исследований. Ловушки 1-6 располагались на поле, ловушка 7 находилась на обочине в метре от края поля. Следующие ловушки (8-10) располагались на заросшей разнотравьем и кустарниками обочине поля (рис. 3), переходящей в опушку леса. На затененном участке опушки леса были установлены ловушки 11 и 12 (рис. 4). 


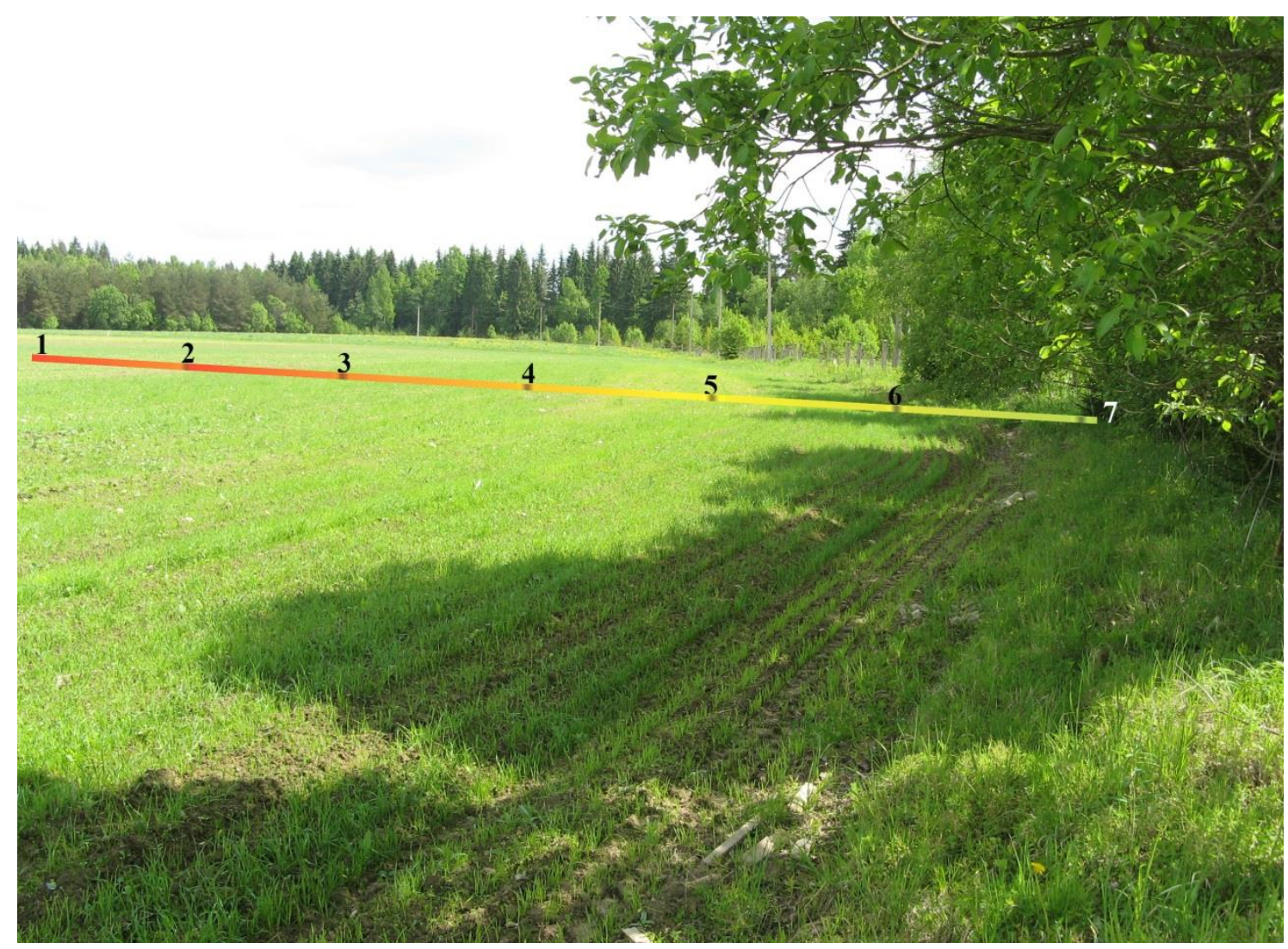

Рис. 2. Поле яровой пшеницы и обочина, места расположения ловушек 1-7.

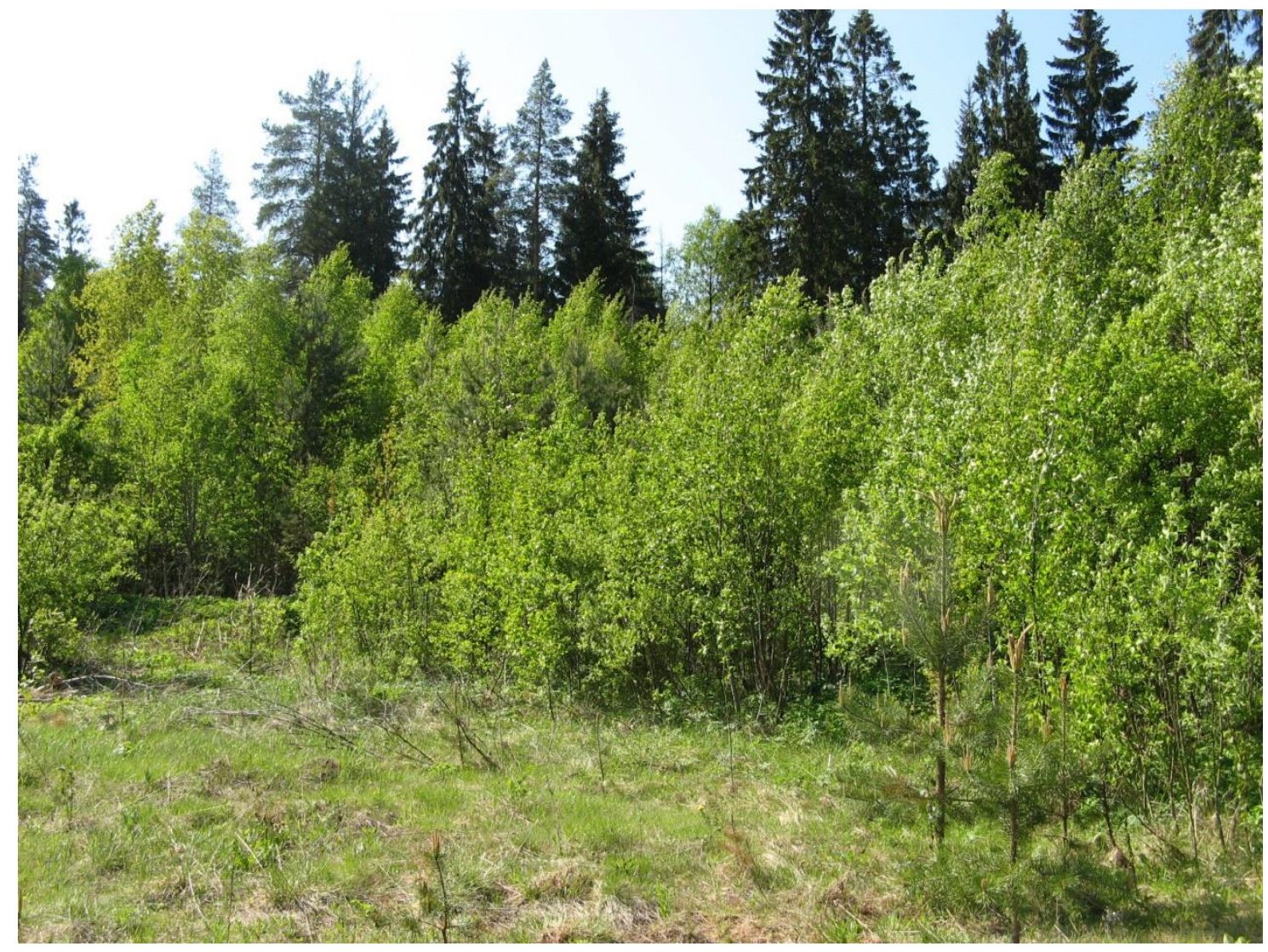

Рис. 3. Обочина поля, участок расположения ловушек 8-10. 


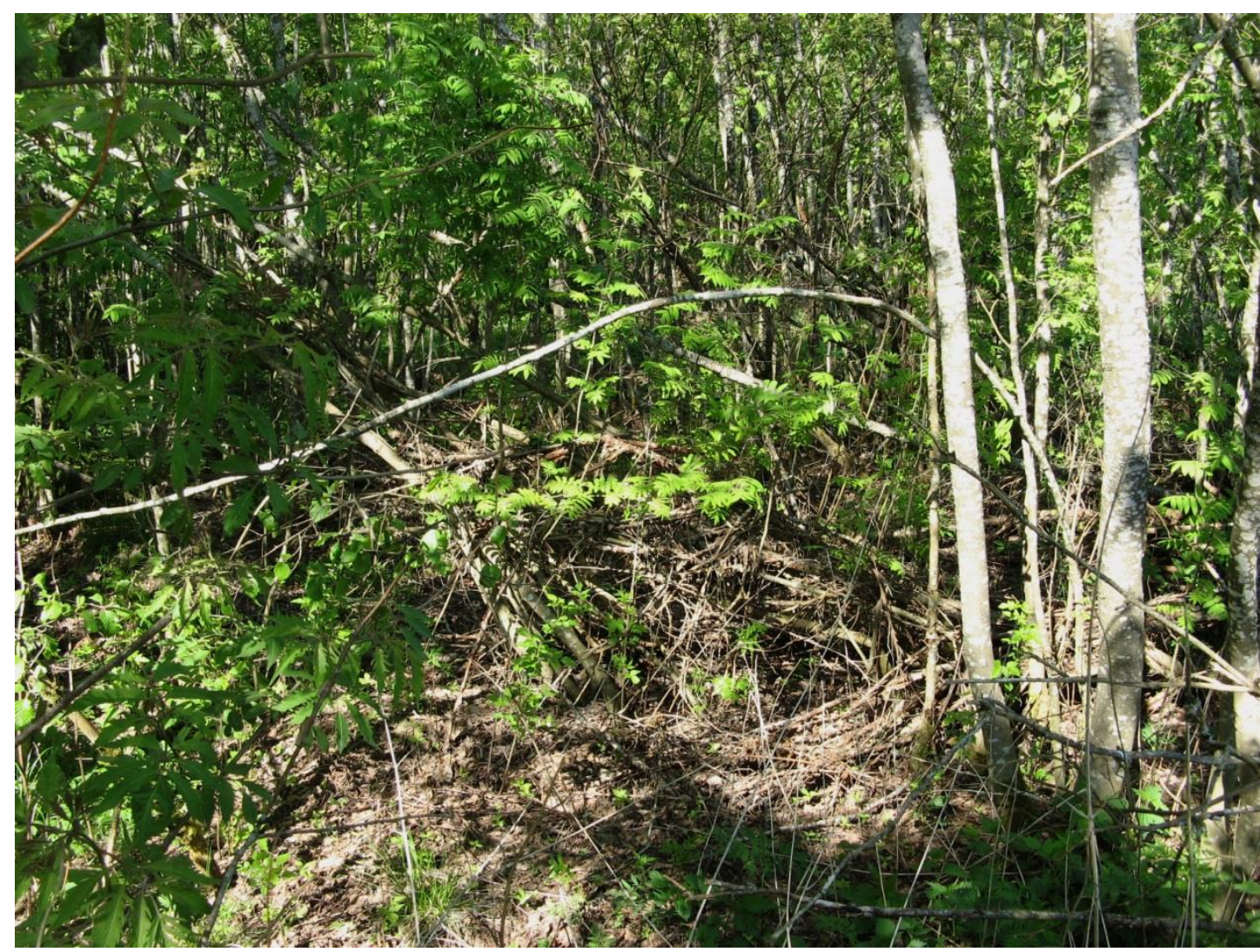

Рис. 4. Опушка леса, участок расположения ловушек 11 и 12.

Выборка ловушек осуществлялась через каждые 15 суток в период с мая по сентябрь. Определение видовой принадлежности собранных жуков проводилось автором в лабораторных условиях. Полученные по ловушкам данные пересчитывали на единицу уловистости - 10 ловушко-суток (л.-с.). Всего за 1128 л.-с. было собрано 1888 жужелиц, из них 382 относились к роду Poecilus.

На основе полученных данных была составлена матрица, записанная в виде таблицы, в которой строки соответствуют отдельным ловушкам, колонки - видам, а в ячейках приведены данные по уловистости каждого вида. Вычисления на основе матрицы проводились в среде языка программирования R (http://www.r-project.org/). Сравнение сборов жужелиц из различных биотопов между собой проводилось путем вычисления дистанционной матрицы с помощью индекса Брея и ее кластеризации различными методами (single, complete).

\section{Результаты и обсуждение}

На поле пшеницы наиболее высокие показатели обилия были характерны для P. cupreus, а на обочине поля для P. versicolor. Отдельные экземпляры P. lepidus встречались как на поле пшеницы, так и на обочине этого поля. Результаты учетов с помощью почвенных ловушек представлены на рисунке 5. На графике показаны значения динамической плотности, или уловистости жужелиц различных видов в отдельных ловушках (рис. 5).

На поле пшеницы жужелицы Р. сupreus составили 65 \% от общего количества собранных жужелиц рода Poecilus. В то же время для обочины поля характерна очень низкая уловистость Р. сupreus. Даже в метре от края поля, где была расположена ловушка номер 7 (рис. 2), за весь летний период были отмечены только отдельные особи P. cupreus. Кластерный анализ подтвердил, что сборы жужелиц рода Роecilus из ловушек 7-10, расположенных на обочине поля, существенно отличаются от сборов из ловушек 1-6, расположенных на поле пшеницы (рис. 6). Это свидетельствует о том, что граница между двумя биотопами - полем и его обочиной является очень существенной для населения жужелиц и проходит по краю обрабатываемой поверхности поля. По мере удаления от края поля наблюдалось дальнейшее уменьшение обилия $P$. cupreus (рис. 5). На опушках леса эти жужелицы не встречаются, в таких условиях регистрируются только отдельные особи $P$. versicolor.

В годы, предшествующие данному исследованию, в том же агроландшафте нами проводились учеты уловистости жужелиц в средней части различных полей, а также на заросших разнотравьем и кустарником обочинах. При этом были получены аналогичные результаты: на полях, занятых различными сельскохозяйственными культурами, среди представителей рода Poecilus преобладали особи $P$. сupreus, а на обочинах - P. versicolor (Guseva, Koval, 2011). Обилие жужелиц P. versicolor на полях возрастало на участках с более густым травостоем. 


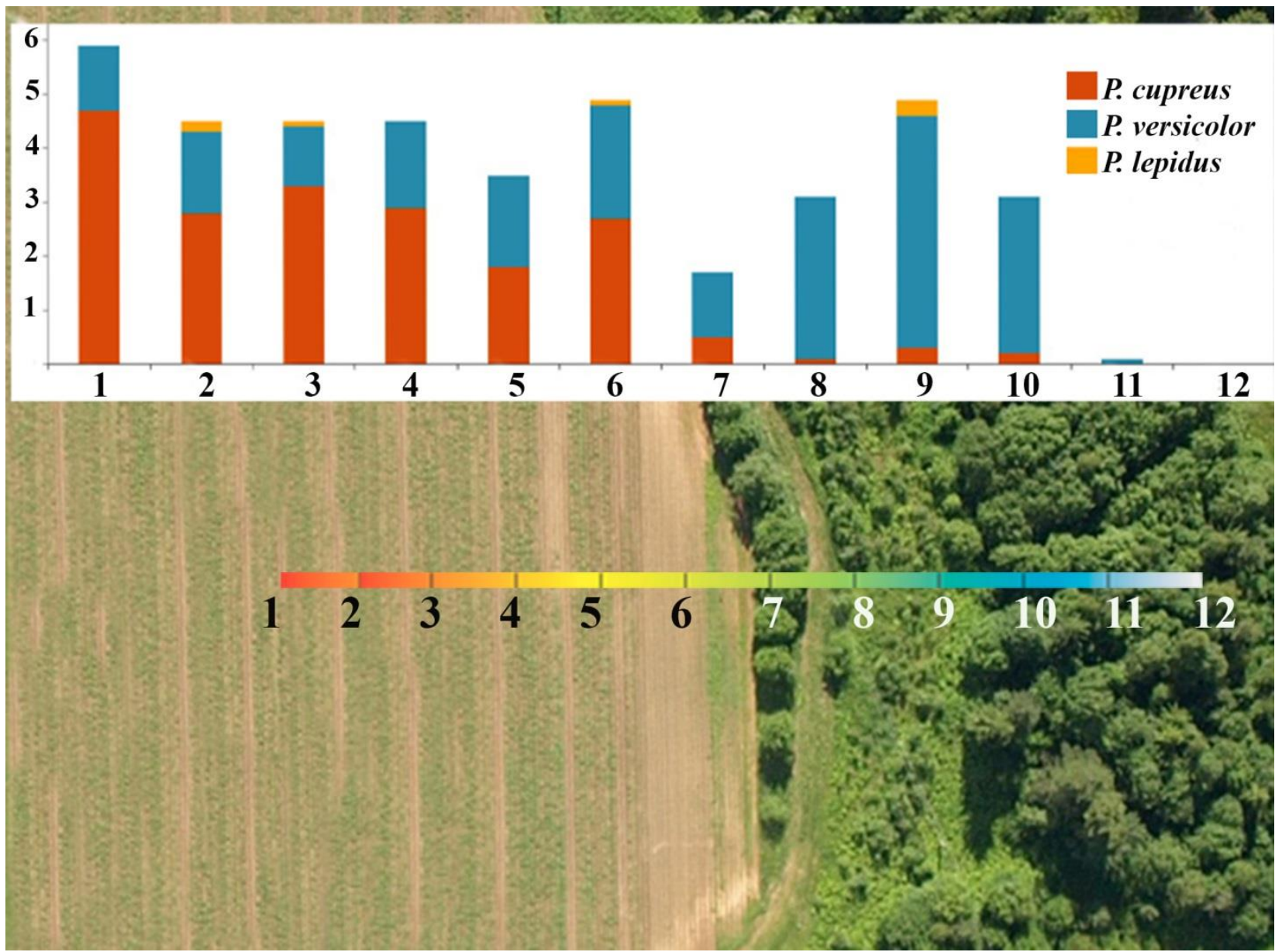

Рис. 5. Динамическая плотность (особей на 10 л.-с.) жужелиц рода Poecilus на различных участках агроландшафта. 1-12- номера ловушек, в соответствии с их расположением в агроландшафте.

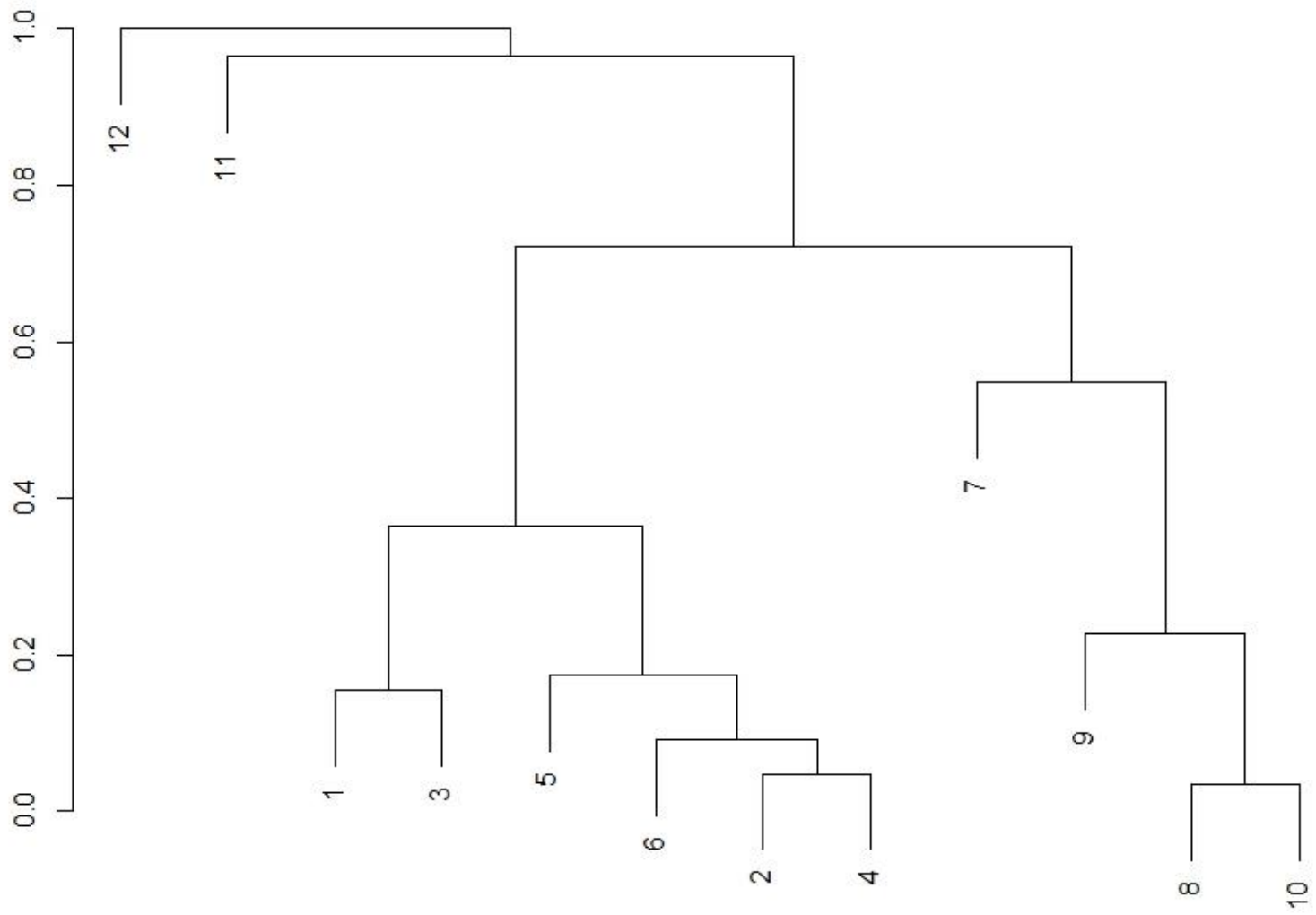

Рис. 6. Дендрограмма сходства комплексов жужелиц рода Роecilus на различных участках агроландшафта. Кластеризация проведена методом complete. Номера ловушек: 1-6 - поле пшеницы, 7-10 - обочина поля, 11 и 12 опушка леса. 
Сходные результаты были получены в Мордовии, где $P$. сирreus является доминантным видом и его обилие составляет 27.1 \% от всех жужелиц агроценозов, максимальная уловистость приходится на поля, а наибольшее количество жуков этого вида отмечено в центральной части посевов, за зоной краевого эффекта. При этом в агроценозах Мордовии обилие P. versicolor составляет лишь 2 \% от всех собранных жужелиц, а представители данного вида чаще встречаются на залуженных участках (Budilov, Budilov, 2007).

Высокие показатели обилия Poecilus cupreus на возделываемых землях объясняются тем, что агроценозы являются важнейшим местом обитания и размножения этих жужелиц. Известно, что на полях, главным образом в центральной их части, происходит развитие личинок этого вида (Wallin, 1988). В агроландшафте МФ АФИ в Ленинградской области личинки P. cupreus были отмечены только на различных полях, а личинки P. versicolor как на полях, так и на примыкающих к ним обочинах (Koval, Guseva, 2016).

Таким образом, жужелицы рода Роесіlus распределяются в агроландшафте неравномерно. Два массовых вида - P. cupreus и P. versicolor отличаются по занимаемому пространству и обилию на различных участках ландшафта. $P$. versicolor распространен шире и встречается практически во всех биотопах, за исключением леса. P. сирrеиs встречается в основном на полях, реже на их обочинах. По показателям обилия на обрабатываемых землях $P$. versicolor уступает близкому виду - P. cupreus. Отдельные особи P. lepidus встречаются только на сухих прогреваемых открытых участках, как на полях, так и за их пределами.

\section{Благодарности}

Работа выполнена в рамках государственного задания № 0665-2014-0009.

\section{References}

Budilov, V.V., Budilov, P.V. (2007). Prostranstvenno-vremennoe raspredelenie karabidofauny (Coleoptera, Carabidae) v agrocenozah Srednego Povolzh'ja. Saransk: Mordovskoe knizhnoe izdatelstvo (In Russian).

Guseva, O.G., Koval, A.G. (2008). Characteristics of carabid complexes (Coleoptera, Carabidae) in agrocenoses of Leningrad region under different soil conditions. Vestnik zashchity rastenij, 4, 3-11 (In Russian).

Guseva, O.G., Koval, A.G. (2010). Food connections of ground beetles Pterostichus melanarius and Poecilus cupreus (Coleoptera, Carabidae). Vestnik zashchity rasteniy, 1, 61-63 (In Russian).

Guseva, O.G., Koval, A.G. (2011). Regional distribution of Carabidae and Staphylinidae in agroecosystem. Selskohoz. biologija, 1, 118-123 (In Russian).

Guseva, O.G., Koval, A.G., Vyazemskaya E.O. (2015). Ground beetles (Coleoptera, Carabidae) of agrolandscapes in the Northwest of Russia and features of their species composition in various agrocenoses. Vestnik Zashchity rasteniy, 4, 2026. (In Russian).

Koval, A.G. (2009). Carabid beetles (Coleoptera, Carabidae) of potato crops in European part of Russia and adjacent territories. St. Petersburg: Russkoe entomologicheskoe obshchestvo (In Russian).

Koval, A.G., Belousov, I.A. (2001). Vozmozhnost' primenenija v zashhite rastenij mestnyh vidov jentomofagov. Entomol. obozrenie, 80, 4, 823-829 (In Russian).

Koval, A.G., Guseva, O.G. (2008). Structure of the ground beetle (Coleoptera, Carabidae) complexes in the potato field agrocenoses on different soils in Northwestern Russia. Entomol. obozrenie, 87(2), 303-312 (In Russian).

Koval, A.G., Guseva, O.G. (2016). A study of distribution of the ground beetles larvae (Coleoptera, Carabidae) in field crop rotations. Vestnik zashchity rasteniy, 2 (88), 26-32 (In Russian).

Lindroth, C.H. (1985). The Carabidae (Coleoptera) of Fennoscandia and Denmark. Copenhagen: Scand. Sc. Prcss Ltd., 1-227. (Fauna Entomol. Scand, 15, I).

Sunderland, K.D. (2002). Invertebrate pest control by carabids. The agroecology of carabid beetles. Andover: Intercept, 165-214.

Wallin, H. (1988). The effects of spatial distribution on the development and reproduction of Pterostichus cupreus L., $P$. melanarius III., P. niger Schall. and Harpalus rufipes DeGeer (Col., Carabidae) on arable land. J. Appl. Entomol., 106, 5, 483487.

\section{Citation:}

Guseva, O.G. (2018). Distribution of ground beetles of the genus Poecilus Bonelli, 1810 (Coleoptera, Carabidae) in the agrolandscape in Northwestern Russia. Acta Biologica Sibirica, 4 (3), 102-107.

Submitted: 13.06.2018. Accepted: 05.08.2018

cross ref http://dx.doi.org/10.14258/abs.v4i3.4414

(C) 2018 by the authors. Submitted for possible open access publication under the terms and conditions of the

Creative Commons Attribution (CC BY) license (http://creativecommons.org/licenses/by/4.0/). 